\title{
Binding of levomepromazine and cyamemazine to human recombinant dopamine receptor subtypes
}

\author{
Lalit K. Srivastava*,** \\ Neelakanta P.V. Nair ${ }^{\star, \star \star}$ \\ Samarthji Lal ${ }^{*, \star *, \star \star *}$
}

* Douglas Mental Health University Institute, Montreal, Quebec

** Department of Psychiatry, McGill University

Department of Psychiatry, Montreal General Hospital, Montreal, Quebec

CANADA

\begin{abstract}
Background and Objectives: Clozapine (CLOZ) and levomepromazine (LMP) improve treatment-resistant schizophrenia. The superior efficacy of CLOZ compared with other antipsychotic agents has been attributed to an effect on D1-like and D4 receptors. We examined the binding of LMP, CLOZ and cyamemazine (CMZ), a neuroleptic analog of LMP, to human recombinant dopamine (rDA) receptor subtypes.

Methods: Binding studies were performed on frozen membrane suspensions of human rDA receptor subtypes expressed in $\mathrm{Sf} 9$ cells.

Results: (i) LMP has a high affinity $(\mathrm{Ki}, \mathrm{nM})$ for $\mathrm{rD} 2$ receptor subtypes ( $\mathrm{rD} 2 \mathrm{~L}$ 8.6; rD2S 4.3; rD3 8.3; rD4.2 7.9); (ii) LMP and CLOZ have comparable affinities for the rD1 receptor (54.3 vs 34.6); (iii) CMZ has high affinities for $\mathrm{rD2}$-like and $\mathrm{rD1}$-like receptors (rD2L 4.6; rD2S 3.3; rD3 6.2; rD4.2 8.5; rD1 3.9; rD5 10.7); (iv) CMZ is 9 times more potent than CLOZ at the rD1 receptor and 5 times more potent than CLOZ at the rD4.2 receptor; (v) CMZ has high affinities for $\mathrm{rD1}$ and $\mathrm{rD5}$ receptor subtypes compared with LMP and CLOZ.

Conclusions: If D1 and D4 receptors are important sites for the unique action of CLOZ, the present study points to a need for clinical trials comparing CMZ with CLOZ in schizophrenia and in particular, treatment-resistant schizophrenia, especially given the risk for agranulocytosis with CLOZ.
\end{abstract}




\section{Background and Objectives}

The dopamine (DA) hypothesis of schizophrenia implicates an enhancement of DA function in the pathophysiology of schizophrenia $^{1-3}$, at least with respect to positive symptoms ${ }^{4}$. All typical and atypical neuroleptics impair DA neurotransmission ${ }^{5,6}$. Subtypes of DA receptors have been identified, namely, D1-like (D1, D5) and D2-like (D2, D3, D4) ${ }^{7}$. Aside from reserpine, which depletes presynaptic DA, neuroleptics impair DA neurotransmission by blocking DA D2 receptors and do so in direct relation to their clinical antipsychotic potencies ${ }^{7}$. Neuroleptics show differences in their binding affinity for the various DA receptor subtypes ${ }^{7}$. Various authors have pointed to specific DA receptor subtypes as mediating the symptoms of schizophrenia and being the principle site of action of neuroleptics, namely, the $\mathrm{D} 4^{8}$, D3 ${ }^{9,10}$ or D1-like subtypes ${ }^{11}$. The superior efficacy of clozapine (CLOZ) in treating schizophrenia, especially in treatment-resistant schizophrenia ${ }^{12}$ has been attributed to antagonism at the D4 receptor ${ }^{8}$.

Following two open studies ${ }^{13,14}$, it has recently been shown that levomepromazine
(LMP) also improves treatment-resistant schizophrenia ${ }^{15}$. LMP, a phenothiazine neuroleptic which is structurally similar to chlorpromazine (CPZ), has a methoxy group at carbon 2 of the phenothiazine ring instead of a chlorine atom and a methyl group at carbon 2 of the aliphatic side chain (Fig. 1). Cyamemazine (CMZ), also a clinically effective neuroleptic ${ }^{16,17}$, is an analog of LMP which differs from LMP in having a cyano group at carbon 2 of the phenothiazine ring instead of a methoxy group (Fig. 1). Neither LMP nor CMZ are marketed as antipsychotics in the United States. In Canada LMP is available for the treatment of schizophrenia but when used is usually prescribed as an adjunctive agent for its sedative-hypnotic effects. In France CMZ is the most frequently prescribed neuroleptic in the treatment of schizophrenia ${ }^{18}$.

Dopamine (DA) receptor binding studies with $\mathrm{LMP}^{19-21}$ or $\mathrm{CMZ}^{22-24}$ have been few and none have looked at the full spectrum of DA receptor subtypes. In view of current theories implicating specific subtypes of DA receptors in the pathophysiology of schizophrenia and the demonstration that both CLOZ and LMP improve treatment-resistant schizophrenia, we

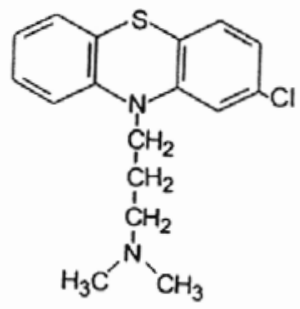

CPZ

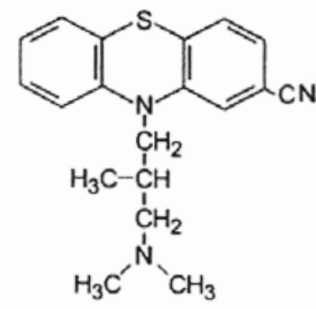

CMZ

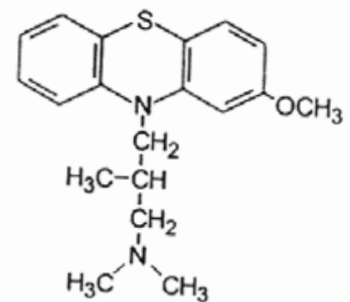

L.MP

Figure 1. CPZ (Chlorpromazine), 2-chloro-10-(3-[dimethylamino]-propyl)-phenothiazine; CMZ (Cyamemazine), 2-cyano-10-(3-[dimethylamino]-2-methyl-propyl)-phenothiazine; LMP (Levomepromazine), 10-(3-[dimethylamino]-2-methyl-propyl)-2-methoxy-phenothiazine. 
have investigated the binding of LMP and CMZ to human recombinant DA receptor subtypes and compared the binding affinities of LMP and CMZ to those of CLOZ.

\section{Methods}

Frozen membrane suspensions of recombinant human dopamine receptor subtypes expressed in Sf9 cells were purchased from Bio-Signal, Montreal. Radioligands for D2 receptor $[3 \mathrm{H}]$ spiperone $(15-30 \mathrm{Ci} / \mathrm{mmol})$ and D1 receptor ${ }^{3} \mathrm{H}-\mathrm{SCH} 23390(70-80 \mathrm{Ci} / \mathrm{mmol})$ were purchased from NEN Dupont. CMZ and LMP were gifts from Rhône Poulenc Pharma. Other drugs and chemicals were obtained from RBI.

The competition assay for drug binding to receptor radioligands was done in triplicate in $1.0 \mathrm{ml}$ assay buffer $(50 \mathrm{mM}$ TrisEDTA, $\mathrm{pH} \mathrm{7.4,} 154 \mathrm{mM} \mathrm{NaCl}$ ) containing $0.22 \mathrm{nM}{ }^{3} \mathrm{H}$-spiperone (for the D2L, D2S, D3 and D4.2) or $1.6 \mathrm{nM}[3 \mathrm{H}] \mathrm{SCH} 23390$ (for the D1 and D5), different concentrations of neuroleptics $(0.1 \mathrm{nM}-10 \mu \mathrm{M})$ and 1 unit of membrane preparations. Non-specif- ic binding was assayed in parallel in the presence of $10 \mu \mathrm{M}(+)$ butaclamol. Incubation was carried out at $25^{\circ} \mathrm{C}$ for $60 \mathrm{~min}$ (D2) or $90 \mathrm{~min}$ (D1) at the end of which the contents were filtered on Whatman $\mathrm{GF} / \mathrm{B}$ filters. The filters were washed four times with $5 \mathrm{ml}$ of ice-cold Tris-EDTA buffer. Radioactivity bound to the filters was determined by placing the filters in scintillation cocktail (Packard) and counting, after an overnight equilibration, in a Beckman Scintillation counter. Competition data were analyzed by Prism software to obtain Ki (inhibitor constant, $\mathrm{nM}$ ) values for drugs.

Data were analyzed by the two-tailed Student's t-test.

\section{Results}

Results are shown in the Table. Noteworthy are (i) high affinities of LMP for rD2L, rD2S, rD3 and rD4.2 receptors; (ii) LMP and CLOZ have a similar order of magnitude of affinity for the $\mathrm{rD} 1$ receptor (54.3 vs 34.6) ( $\mathrm{p}=\mathrm{NS}$ ); (iii) $\mathrm{CMZ}$ has high affinities for the $\mathrm{rD} 2 \mathrm{~L}, \mathrm{rD} 2 \mathrm{~S}, \mathrm{rD} 3, \mathrm{rD} 4.2, \mathrm{rD} 1$ and

Table I

Affinities of drugs $(\mathrm{Ki}, \mathrm{nM}$, Mean $\pm \mathrm{SE}, \mathrm{N}=3)$ for human recombinant dopamine receptors

Drug

Dopamine Receptor Subtypes

\begin{tabular}{|c|c|c|c|c|c|c|}
\hline & $\mathrm{rD} 2 \mathrm{~L}$ & $\mathrm{rD} 2 \mathrm{~S}$ & rD3 & $\mathrm{rD} 4.2$ & rD1 & rD5 \\
\hline LMP & $8.6 \pm 1.3$ & $4.3 \pm 0.6$ & $8.3 \pm 0.9$ & $7.9 \pm 1.0$ & $54 \pm 2.9$ & $48 \pm 4.4$ \\
\hline $\mathrm{CMZ}$ & $4.6 \pm 0.8$ & $3.3 \pm 0.8$ & $6.2 \pm 1.1$ & $8.5 \pm 1.0$ & $3.9 \pm 0.2$ & $10.7 \pm 0.6$ \\
\hline $\mathrm{CMZ} \dagger$ & \multicolumn{2}{|c|}{$5.8 \pm 0.84$} & $2.5 \pm 0.5$ & $5.3 \pm 0.5^{*}$ & \multicolumn{2}{|c|}{$3.8 \pm 0.6 * *$} \\
\hline CLOZ & $225 \pm 19$ & $229 \pm 31$ & $1181 \pm 7.9$ & $41 \pm 2.8$ & $35 \pm 2.2$ & $282 \pm 24$ \\
\hline CPZ & 3बI & - & 4 & 35 & 90 & 130 \\
\hline HAL $\ddagger$ & $1.2 \pi$ & - & 7 & 2.3 & 80 & 100 \\
\hline
\end{tabular}

$\mathrm{LMP}=$ levomepromazine $\mathrm{CMZ}=$ cyamemazine $\mathrm{CLOZ}=$ clozapine $\mathrm{CPZ}=$ chlorpromazine $\mathrm{HAL}=$ haloperidol .

$\dagger$ Data from Hameg et al. ${ }^{23}$; recombinant receptors expressed in $\mathrm{CHO}$ cells.

$\$$ Data from Seeman and Van $\mathrm{Tol}^{7}$.

II rD2L not distinguished from rD2S;

* Values for rD4.4

** rD1 not distinguished from rD5. 
rD5 receptors; (iv) $\mathrm{CMZ}$ is nine times more potent than CLOZ at the $\mathrm{rD} 1$ receptor $(\mathrm{p}<$ $0.001)$ and five times more potent than CLOZ at the rD4.2 receptor ( $<<0.001)$; (v) $\mathrm{CMZ}$ has high affinities for the rD1 and rD5 receptors compared with LMP and CLOZ ( $p<0.001$ for all four comparisons).

\section{Discussion}

In binding studies in autopsied human brain frontal cortex, the binding affinity of LMP and CPZ to D2-like receptors (using ${ }^{3} \mathrm{H}$-spiperone) was considerably greater than for D1-like receptors (using ${ }^{3} \mathrm{H}-\mathrm{SCH}-23390$ ), namely 23.5 and 30.7 times greater, respectively, whereas for CLOZ it was only 1.2 times greater ${ }^{19}$. In the present study using human rDA receptor subtypes the binding affinities of LMP for the $\mathrm{rD} 2 \mathrm{~L}, \mathrm{rD} 2 \mathrm{~S}, \mathrm{rD} 3$ and $\mathrm{rD} 4.2$ receptors, respectively, were 6.3 , 12.6, 6.5 and 6.8 times greater than the affinity for D1 receptors and 5.6, 11.2, 5.8 and 6.1 times greater, respectively, than affinity for the rD5 receptor. For CLOZ the binding affinity to the $\mathrm{rD} 1$ receptor was considerably greater than for the affinity for the rD2L, $\mathrm{rD} 2 \mathrm{~S}$, and $\mathrm{rD} 3$ and approximately equipotent in binding to the $\mathrm{D} 4.2$ receptor. The binding affinity of CLOZ to the rD5 receptor was approximately equipotent to the binding affinity to the rD2L and rD2S, and 4.2 times greater for the rD3 receptor. The binding affinity of CLOZ to the rD4.2 receptor was 6.9 times greater than for the $\mathrm{rD} 5$ receptor.

The superior efficacy of CLOZ in treating schizophrenia, especially in treatment-resistant schizophrenia ${ }^{12}$ has been attributed to antagonism at the D4 receptor as well as other neurotransmitter receptor targets. D4 receptors are increased 6-fold compared with only a $10 \%$ increase in D2 and D3 receptors in schiz- ophrenia ${ }^{8}$ and cloned D4 receptors are blocked at CLOZ concentrations that are found in the spinal fluid from CLOZ treated patients ${ }^{7}$. In the present study both LMP and CMZ showed a greater affinity for the D4 receptor than CLOZ. However, the affinity of haloperidol, which is ineffective in treatment-resistant schizophrenia ${ }^{12,15}$ has a much greater binding affinity for the D4 receptor than $\mathrm{CLOZ}^{7}$. Further, the selective D4 antagonist, sonepiprazole, was without clinical benefit in patients with schizophrenia ${ }^{25}$ (in the doses used).

Both CLOZ ${ }^{12}$ and $\mathrm{LMP}^{15}$ improve treatment-resistant schizophrenia. The only similarity in DA receptor binding in our study is the affinity for the rD1 receptor. Compared with reported $\mathrm{Ki}$ values, CLOZ has a 2.6 and 2.3 times greater affinity for the rD1 receptor than CPZ and HAL, respectively? Thus, the Ki values for CLOZ, LMP, CPZ and HAL for the rD1 receptor are of a similar order of magnitude. This may indicate that D1 receptors are important targets for antipsychotic activity. In this regard, CLOZ binds preferentially to cortical D1-like DA receptors in primate brain ${ }^{11}$. Further, chronic treatment with CLOZ and other antipsychotic agents down regulates D1 (and D5) receptors in primate prefrontal cortex ${ }^{26,27}$.

Hameg et al. ${ }^{23}$ investigated $\mathrm{CMZ}$ binding to human $\mathrm{rDA}$ receptors expressed in $\mathrm{CHO}$ cell lines but did not distinguish rD2L from $\mathrm{rD} 2 \mathrm{~S}$ or $\mathrm{rD} 1$ from $\mathrm{rD} 5$. Our findings are of a similar order of magnitude to those of Hameg et al. $^{23}$. CMZ has a high affinity for the $\mathrm{rD} 1$ and $\mathrm{rD} 4$ receptors. The affinity of $\mathrm{CMZ}$ for the $\mathrm{rD} 1$ and the $\mathrm{rD} 4$ receptors is nine times and five times, respectively, more than that of CLOZ. If D1 and D4 receptors are important in the neuroleptic activity of CLOZ and other antipsychotic agents, then CMZ may have an important role in the management of treatment-resistant schizophrenia. This is of particular importance as CLOZ 
treatment is associated with a two percent cumulative incidence of agranulocytosis after 52 weeks of treatment ${ }^{28}$. Unfortunately, well controlled studies comparing $\mathrm{CMZ}$ to other neuroleptics have not been undertaken. Nurowska ${ }^{17}$ in a parallel design study comparing CMZ with LMP showed $88 \%$ of patients improved on CMZ and $86 \%$ on LMP. $\mathrm{CMZ}$ was better tolerated. The investigation, however, was an open study. Both CMZ and CLOZ affect many receptor types aside from DA so that a contribution of non-DA receptors, namely, serotonin receptor subtypes ${ }^{29}$, muscarinic M1 and glutamate receptors to the antipsychotic efficacy of these agents cannot be excluded. However, the DA hypothesis remains viable and given the focus on antagonism at the D1 and D4 receptors in the pathophysiology of schizophrenia, the finding that $\mathrm{CMZ}$ has a considerably greater affinity than CLOZ for D1 and D4 receptor sites points to the need for studies comparing the efficacy of CMZ to CLOZ, especially in treatment-resistant schizophrenia.

\section{Acknowledgements}

This work was supported by the Medical Research Council (Canada), now called Canadian Institutes of Heath Research (CIHR), and former Rhône Poulenc Pharma. We thank Nadia Zajac for secretarial assistance.

\section{References}

1. Breier A, Su TP, Saunders R, Carson RE, Kolachana BS, de Bartolomeis A, et al. Schizophrenia is associated with elevated amphetamine-induced synaptic dopamine concentrations: evidence from a novel positron emission tomography method. Proc Natl Acad Sci USA 1997; 94 : 2569-2574.

2. Abi-Dargham A, Gil R, Krystal J, Baldwin RM, Seibyl JP, Bowers M, et al. Increased striatal dopamine transmission in schizophrenia: confirmation in a second cohort. Am J Psychiatry 1998; 155: 761-767.

3. Seeman P, Weinshenker D, Quirion R, Srivastava L, Bhardwaj SK, Grandy DK, et al. Dopamine supersensitivity correlates with D2 ${ }^{\text {high }}$ states, implying many paths to psychosis. Proc Natl Acad Sci USA 2005; 102: 3513-3518.

4. Davis KL, Kahn RS, Ko G, Davidson M. Dopamine in schizophrenia: a review and reconceptualization. Am J Psychiatry 1991; 148: 1474-1486.

5. Kapur S, Mamo D. Half a century of antipsychotics and still a central role for dopamine D2 receptors. Prog Neuropsychopharmacol Biol Psychiatry 2003; 27: 10811090 .

6. Kapur S, Remington G. Dopamine D2 receptors and their role in atypical antipsychotic action: still necessary and may even be sufficient. Biol Psychiatry 2001; 50: 873883.

7. Seeman P, Van Tol HHM. Dopamine receptor pharmacology. Trends Pharmacol Sci 1994; 15: 264-270.

8. Seeman P, Guan HC, Van Tol HHM. Dopamine D4 receptors elevated in schizophrenia. Nature 1993; 365: 441-445.

9. Sokoloff P, Martres MP, Giros B, Bouthenet ML, Schwartz, JC. The third dopamine receptor $\left(D_{3}\right)$ as a novel target for antipsychotics. Biochem Pharmacol 1992; 43: 659-666.

10. Dépatie L, Lal S. Apomorphine and the dopamine hypothesis of schizophrenia: a dilemma? J Psychiatry Neurosci 2001; 26: 203-220.

11. Chou YH, Halldin C, Farde L. Clozapine binds preferentially to cortical D1-like dopamine receptors in the primate brain: a PET study. Psychopharmacology 2006; 185 : 29-35.

12. Kane JM, Honigfeld G, Singer J, Meltzer H and the Clozaril Collaborative Study Group. Clozapine for the treatment resistant schizophrenic: a double-blind comparison with chlorpromazine. Arch Gen Psychiatry 1988; 45: 789-796.

13. Lal S, Nair NPV. Is levomepromazine a useful drug in treatment-resistant schizophrenia? Acta Psychiatr Scand 1992; 85: 243-245.

14. Jones B, Labelle A, Fraser H, Bedard D, Brideau R. Methotrimeprazine: an alternative to clozapine in treat- 
ment-refractory schizophrenia. Clin Neuropharmacol 1992; 15 (Suppl 1): 364.

15. Lal S, Thavundayil JX, Nair NPV, Annable L, Ng Ying Kin NMK, Gabriel A, et al. Levomepromazine versus chlorpromazine in treatment-resistant schizophrenia: a double-blind randomized trial. J Psychiatry Neurosci 2006; 31: 271-279.

16. Paleologue A, Varouchakis H. Etude de l'activite therapeutique d'un nouveau neuroleptique 7204 RP. Inf Psychiatr 1976; 52: 249-256.

17. Nurowska K. A clinical evaluation of cyamemazine. Psychiatr Pol 1983; 17:389-395.

18. Brunot A, Lachaux B, Sontag H, Casadebaig F, Philippe A, Rouillon F, et al. Étude pharmaco-épidémiologique de la prescription des antipsychotiques en milieu psychiatrique en France - Profil et prise en charge du patient schizophrène traité par antipsychotiques. Encéphale 2002; 28: 129-138.

19. Lal S, Nair NPV, Cecyre D, Quirion R. Levomepromazine receptor binding profile in human brain - implications for treatment-resistant schizophrenia. Acta Psychiatr Scand 1993; 87: 380-383.

20. Dahl SG, Hall H. Binding affinity of levomepromazine and two of its major metabolites to central dopamine and $\alpha$-adrenergic receptors in the rat. Psychopharmacology 1981; 74: 101-104.

21. Kaichi Y, Nonaka R, Hagino Y, Watanabe M. Dopamine $\mathrm{D}_{3}$ receptor binding by $\mathrm{D}_{3}$ agonist 7-OH-DPAT (7-hydroxy-dipropylaminotetralin) and antipsychotic drugs measured ex vivo by quantitative autoradiography. Can J Physiol Pharmacol 2000; 78: 7-11.

22. Garay RP, D’Alché-Birée. Cyamémazine (Tercian ${ }^{\circledR)}$ : Profil neuroleptique ou anxiolytique? Inf Psychiatr 1995; 10: 969-971.

23. Hameg A, Bayle F, Nuss P, Dupuis P, Garay RP, Dib M. Affinity of cyamemazine, an anxiolytic antipsy- chotic drug, for human recombinant dopamine vs serotonin receptor subtypes. Biochem Pharmacol 2003; 65: 435-440.

24. Hodé Y, Reimold M, Demazières A, Reischl G, Bayle F, Nuss P, et al. A positron emission tomography (PET) study of cerebral dopamine $\mathrm{D}_{2}$ and serotonine $5-\mathrm{HT}_{2 \mathrm{~A}}$ receptor occupancy in patients treated with cyamemazine (Tercian). Psycho-pharmacology 2005; 180: 377-384.

25. Corrigan MH, Gallen CC, Bonura ML, Merchant KM and Sonepiprazole Study Group. Effectiveness of the selective $\mathrm{D}_{4}$ antagonist sonepiprazole in schizophrenia: a placebo-controlled trial. Biol Psychiatry 2004; 55: 445-451.

26. Lidow MS, Goldman-Rakic PS. A common action of clozapine, haloperidol, and remoxipride on D1- and D2dopaminergic receptors in the primate cerebral cortex. Proc Natl Acad Sci USA 1994; 91: 4353-4356.

27. Lidow MS, Elsworth JD, Goldman-Rakic PS. Down-regulation of the D1 and D5 dopamine receptors in the primate prefrontal cortex by chronic treatment with antipsychotic drugs. J Pharmacol Exp Ther 1997; 281: $597-$ 603.

28. Lieberman JA, Johns CA, Kane JM. Clozapine-induced agranulocytosis: non-cross reactivity with other psychotropic drugs. J Clin Psychiatry 1988; 49: 271-277.

29. Meltzer HY. The role of serotonin in antipsychotic drug action. Neuropsychopharmacology 1999; 21: 106S$115 \mathrm{~S}$.

Address for correspondence:

S. Lal, MD, FRCP(C)

Douglas Mental Health University Institute

6875 LaSalle Boulveard

Montreal, Quebec H4H 1R3

Telephone: 1-514-934-1934 ext. 42362

Fax: 1-514-934-8471

E-mail: samarthji.lal@muhc.mcgill.ca 